\title{
Erythrodermic psoriasis and human immunodeficiency virus: association and therapeutic challenges*
}

\author{
Fernando Valenzuela ${ }^{1,2}$ \\ Margarita Sánchez ${ }^{1}$
}

\author{
Javier Fernández ${ }^{1}$ \\ Andrea Zamudio ${ }^{3}$
}

DOI: http:/ / dx.doi.org/10.1590/abd1806-4841.20187387

\begin{abstract}
Erythrodermic psoriasis is a rare but severe type of psoriasis that may be triggered by human immunodeficiency virus infection. We describe the case of a 65-year-old male patient with chronic psoriasis who presents an exacerbation of his condition over a period of two weeks. Because of the severity of his case and subsequent need for systemic therapy, human immunodeficiency virus enzyme immunoassay was performed and tested positive. He thus began antiretroviral therapy combined with acitretin, showing good clinical response after 8 weeks of treatment. There is little evidence regarding the management of erythrodermic psoriasis associated with HIV infection, so antiretroviral therapy and systemic retinoid remain as the first-line treatment.
\end{abstract}

Keywords: Acitretin; HIV; Psoriasis

\section{INTRODUCTION}

Psoriasis is a chronic inflammatory skin disease and is prevalent in 2-3\% of the world population. ${ }^{1}$ It has several phenotypes of which erythrodermic psoriasis is an uncommon and severe variant. ${ }^{2}$ It is characterized by erythema involving more than $75 \%$ or $90 \%$ of the body surface area, according to different authors. ${ }^{2,3}$ We present a case of erythrodermic psoriasis associated with a recently detected human immunodeficiency virus (HIV) infection.

\section{CASE REPORT}

A 65-year-old male patient with chronic psoriasis since he was 14 years old attended regular checkups and had irregular topical corticosteroid therapy. Over the course of two weeks, erythematous scaly plaques increased both in extension and depth. The patient reported severe skin pain (10/10 on the visual analogue scale), fever up to $39.7^{\circ} \mathrm{C}$, and weight loss of approximately $3 \mathrm{~kg}$ in two weeks. He was not on any new medication.

Physical examination revealed purple-erythematous plaques with fine scaling on the scalp, trunk, and upper and lower extremities, compromising $90 \%$ of his body surface area (Figure 1).
There were no pustules, and the mucosa was not affected. A complete blood count showed mild leukocytosis (11,590 white blood cells $\mu \mathrm{l}$; $64 \%$ neutrophils, $24 \%$ lymphocytes, $4 \%$ eosinophils), $87 \mathrm{mg} / 1$ C-reactive protein (normal range: $0-10 \mathrm{mg} / \mathrm{l}$ ). Liver enzymes, blood chemistry, kidney function, and electrolytes showed no alterations. Blood culture tested positive for Staphylococcus aureus. The patient was admitted to hospital for workup and management. Skin section showed hyperkeratosis with intracorneal pustules, agranulocytosis, regular acanthosis, dermis with dilated blood vessels, and lymphocyte infiltrate, all these findings being consistent with psoriasis (Figure 2).

Because of the severity of his case and the need for subsequent systemic therapy, HIV enzyme immunoassay was performed, testing positive and later confirmed. Plasma HIV viral load and CD4 cell count were performed, showing 117,000 copies/ $\mathrm{ml}$ and 632 cells/ul, respectively, confirming an acute infection. Systemic antibiotic therapy was administered along with antiretroviral therapy (emtricitabine/tenofovir and raltegravir), associated with acitretin $25 \mathrm{mg}$ once a day, with a good response in 8 weeks.

Received 20 June 2017.

Accepted 05 September 2017.

* Work conducted at the University of Chile, Santiago, Chile.

Financial support: None.

Conflict of interest: None.

Department of Dermatology, Faculty of Medicine, University of Chile, Santiago, Chile.

Department of Dermatology, Clínica Las Condes, Santiago, Chile.

School of Medicine, Faculty of Medicine, University of Chile, Santiago, Chile.

MAILING ADDRESS:

Fernando Valenzuela

E-mail: fvalenzuela.cl@gmail.com 

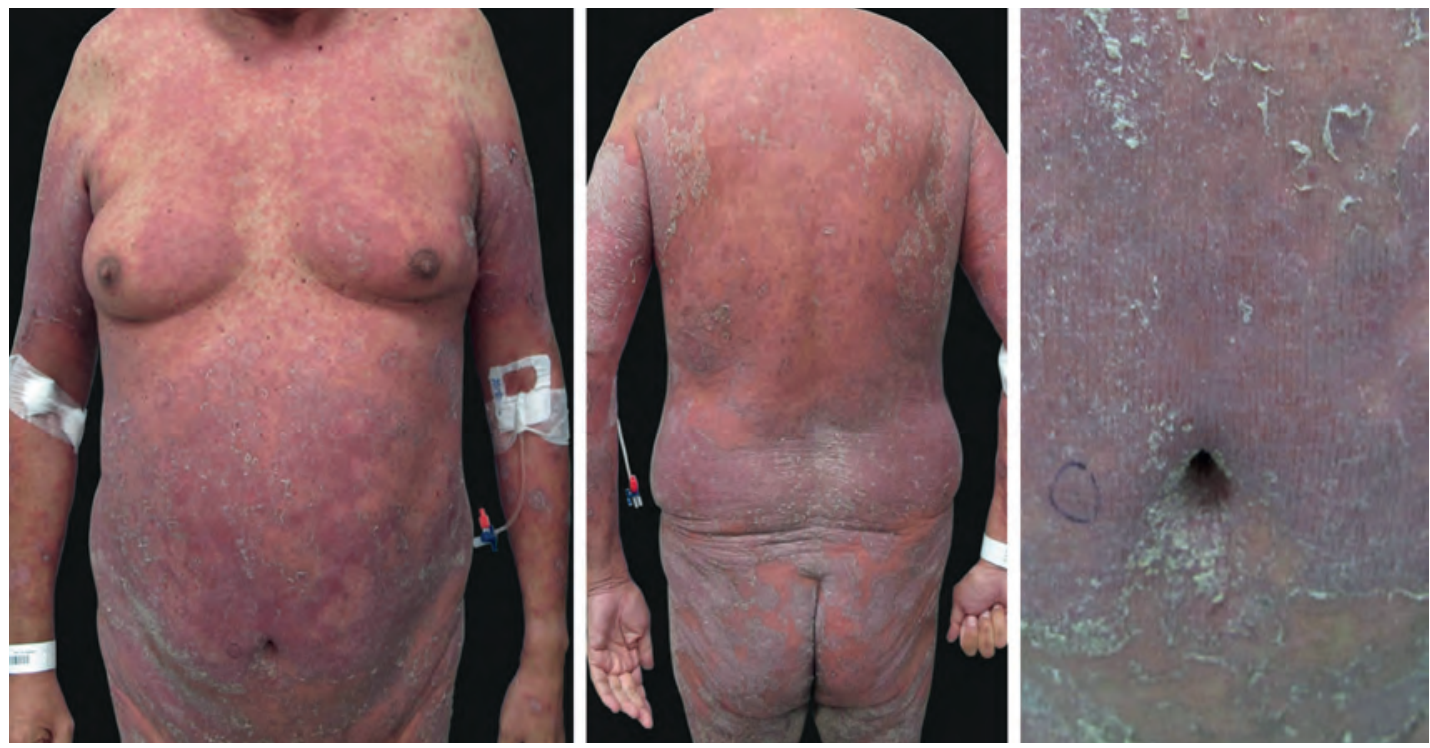

Figure 1: Patient with erythrodermic psoriasis and HIV infection of recent diagnosis. Purplee ry the m a tous plaques with fine scaling extend from trunk to upper and lower extremities

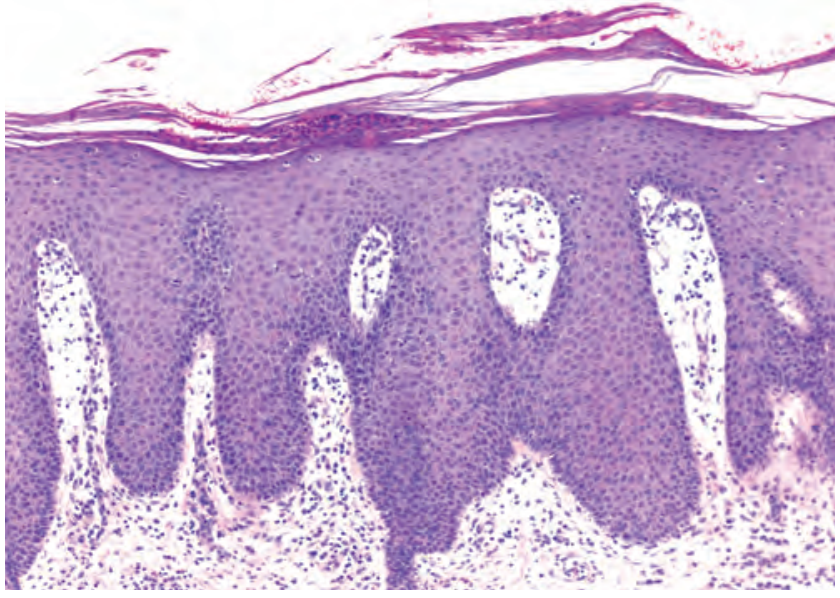

FiguRE 2: Hyperkeratosis and intracorneal pustules, agranulocytosis, regular acanthosis, papillary dermis with dilated blood vessels, and lymphocyte infiltrate Hematoxylin \& eosin, X100

\section{DISCUSSION}

Erythrodermic psoriasis is a rare type of psoriasis, present in $1 \%$ to $2.25 \%$ of all psoriatic patients, ${ }^{2}$ and constitutes the main cause of erythroderma, comprising $25 \%$ of the cases. ${ }^{2}$ Erythrodermic psoriasis mostly presents in adult males, although it has been reported in different age groups, including congenital cases. ${ }^{3}$ Even though erythrodermic psoriasis may be the first manifestation of psoriasis, it usually manifests in patients with longstanding chronic psoriasis, generally 11 to 18 years after diagnosis. ${ }^{3}$

Reported triggering factors include HIV infection, emotional stress, intense ultraviolet light exposure, use of topical tar products, alcoholism, abrupt withdrawal of oral or topical corticosteroids, and methotrexate therapy. Erythrodermic psoriasis is associated with severe and even fatal complications like sepsis, acute kidney damage, respiratory distress, electrolyte imbalance, severe anemia, altered thermoregulation, protein depletion, and cardiac failure. ${ }^{3}$ The prevalence of psoriasis is similar in patients with HIV compared to the general population. ${ }^{4}$ It can appear as the first manifestation of HIV infection and should be suspected in new cases and patients with sudden worsening of previously stable psoriasis. In our case, a high viral load and high CD4 cell count confirmed an acute infection with erythrodermic psoriasis as the first manifestation of HIV infection. Psoriasis can present throughout the course of immunodeficiency, but its severity is proportional to the degree of immunosuppression, being most severe when CD4 count falls below 100 cells per microliter. Even though HIV-associated psoriasis can present with any phenotype, erythrodermic, guttate, and acral psoriasis and psoriatic arthritis tend to appear more frequently than in HIV-negative individuals. ${ }^{4,5}$

There are no trials or guidelines on the treatment of erythrodermic psoriasis in patients with HIV infection. Treatment of moderate to severe HIV-associated psoriasis poses a therapeutic challenge, since most systemic treatments are immunosuppressive and could lead to severe complications. In 2010 the Psoriasis National Foundation recommended ${ }^{6}$ antiretroviral therapy as the first line of treatment for HIV-associated psoriasis, which was reported to be effective in a number of cases and clinical trials. Antiretroviral therapy includes nucleoside and non-nucleoside reverse transcriptase inhibitors, protease inhibitors, and fusion inhibitors and has demonstrated improvement in HIV-associated psoriasis. Phototherapy with either ultraviolet $B$ radiation or psoralen and ultraviolet $A$ is another firstline treatment recommended for patients with moderate to severe HIV-associated psoriasis without erythroderma. ${ }^{6}$ However, one must balance the benefits of ultraviolet $\mathrm{A}$ exposure against the potential risk of skin cancer, the potential rise in HIV recount, and the risks secondary to the use of photosensitizing drugs. Oral retinoids are an effective alternative that do not cause immunosuppression, ${ }^{1,7}$ and may be given together with psoralen and ultraviolet A radiation.

Cyclosporine, methotrexate, and biological drugs (anti-tumor necrosis factor and anti-interleukins 12 to 23) are reserved for refractory cases. ${ }^{6,8}$ Because in vitro studies show that TNF stimulates 
HIV intracellular transcription, biological therapy targeting TNF could be effective, although this benefit should be balanced against the augmented risk of opportunistic infections and the fact that TNF is involved in granuloma formation. There is scarce experience using etanercept, infliximab, adalimumab, and ustekinumab. ${ }^{8-10}$ Indi- cation for the use of the first-line biological agents is unclear, and they may be considered an effective choice for patients with stable HIV infection who are adherent to medication and have failed to respond to other psoriasis treatment modalities. ${ }^{8,9}$

\section{REFERENCES}

1. Pathirana D, Ormerod AD, Saiag P, Smith C, Spuls PI, Nast A, et al. European S3 guidelines on the systemic treatment of psoriasis vulgaris. J Eur Acad Dermatol Venereol. 2009;23:1-70.

2. Rosenbach M, Hsu S, Korman NJ, Lebwohl MG, Young M, Bebo BF Jr, et al. Treatment of erythrodermic psoriasis: from the medical board of the National Psoriasis Foundation. J Am Acad Dermatol. 2010:62:655-62.

3. Hawilo A, Zaraa I, Benmously R, Mebazaa A, El Euch D, Mokni M, et al. Erythrodermic psoriasis: epidemiological clinical and therapeutic features about 60 cases. Tunis Med. 2011;89:841-7.

4. Cedeno-Laurent F, Gómez-Flores M, Mendez N, Ancer-Rodríguez J, Bryant JL, Gaspari AA, et al. New insights into HIV-1-primary skin disorders. J Int AIDS Soc. 2011;14:5.

5. Castillo RL, Racaza GZ, Roa FD. Ostraceous and inverse psoriasis with psoriatic arthritis as the presenting features of advanced HIV infection. Singapore Med J. 2014;55:e60-3
6. Menon K, Van Voorhees AS, Bebo BF Jr, Gladman DD, Hsu S, Kalb RE, et al. Psoriasis in patients with HIV infection: from the medical board of the National Psoriasis Foundation. J Am Acad Dermatol. 2010;62:291-9.

7. Itoi-Ochi S, Hayashi M, Yamaoka T, Kobayashi Y, Isei T, Shirasaka T, et al. Occult HIV infection in Japanese rupioid psoriasis. J Dermatol. 2017;44:e172-e173.

8. Bardazzi F, Magnano M, Campanati A, Loconsole F, Carpentieri A, Potenza C, et al. Biologic Therapies in HIV-infected Patients with Psoriasis: An Italian Experience. Acta Derm Venereol. 2017:97:989-990.

9. Gallitano SM, McDermott L, Brar K, Lowenstein E. Use of tumor necrosis factor (TNF) inhibitors in patients with HIV/AIDS. J Am Acad Dermatol. 2016;74:974-80.

10. Saeki H, Ito T, Hayashi M, Fukuchi 0, Umezawa Y, Nobeyama Y, et al. Successful treatment of ustekinumab in a severe psoriasis patient with HIV infection. J Eur Acad Dermatol Venereol. 2015;29:1653-5.

$\begin{array}{ll}\text { Fernando Valenzuela } & \text { (D) ORCID 0000-0003-1032-9347 } \\ \text { Javier Fernández } & \text { (iD) ORCID 0000-0002-7110-3600 }\end{array}$

\section{Margarita Sánchez}

Andrea Zamudio
ORCID 0000-0002-1104-6309

ORCID 0000-0003-2569-2915

How to cite this article: Valenzuela F, Fernández J, Sánchez M, Zamudio A. Erythrodermic psoriasis and human immunodeficiency virus: association and therapeutic challenges. An Bras Dermatol. 2018;93(3):438-40. 